\title{
GNOSTIC DISAGREEMENT NORMS
}

\author{
Domingos Faria ${ }^{1}$ \\ ${ }^{1}$ LanCog, Centre of Philosophy, University of Lisbon \\ Original scientific article - Received: 29/08/2021 Accepted: 26/01/2022
}

\begin{abstract}
Our main question in this paper is as follow: (Q) What are the epistemic norms governing our responses in the face of disagreement? In order to answer it, we begin with some clarification. First, following McHugh (2012), if we employ a useful distinction in normativity theory between evaluative and prescriptive norms, there are two readings of $(Q)$-we explore such distinction in section 2. And secondly, we accept gnosticism, that is, the account that the fundamental epistemic good is knowledge. It is with this assumption that we want to answer $(Q)$. So, if gnosticism is true, what is the plausible answer to $(Q)$ ? In section 3 we argue for gnostic disagreement norms as response to $(Q)$ and in section 4 we apply such norms to particular cases of disagreement.
\end{abstract}

Keywords: disagreement; evaluative norms; prescriptive norms; disagreement norms; gnostic disagreement norms; knowledge-first epistemology. 


\section{Introduction}

Our main question in this paper is as follows:

(Q) What are the epistemic norms governing our responses in the face of disagreement?

With this question we want disagreement norms not only for cases of peer and idealized disagreement, but also for ordinary or daily cases of disagreement. Thus, we intend to propose norms that target all types of disagreement. ${ }^{1}$ In order to answer question (Q), we begin with some clarification. First, following Conor McHugh (2012), if we employ a useful distinction in normativity theory between evaluative and prescriptive norms, there are two readings of $(\mathrm{Q})$ - we explore such distinction in section 2. And secondly, we accept gnosticism (see Williamson 2000; Littlejohn and Dutant 2021), that is, the account that the fundamental epistemic good is knowledge. It is with this assumption that we want to answer (Q). Roughly, we are assuming gnosticism because (i) it gives a good account of the value of knowledge ${ }^{2}$ and (ii) its consequences for the case of disagreement are hitherto unexplored. ${ }^{3}$ So, if gnosticism is true, what is the plausible answer to (Q)? In section 3 we argue for gnostic disagreement norms as response to (Q) and in section 4 we apply such norms to particular cases of disagreement. As the main contribution of this paper, we highlight the application of the distinction between evaluative and prescriptive norms to key cases of disagreement, based on a gnostic epistemology.

\section{Evaluative and Prescriptive Norms}

In this section, we want to clarify the question (Q). This question will be approached by employing a distinction in normativity theory. Namely, following McHugh (2012), Simion, Kelp, and Ghijsen (2016), and Simion

\footnotetext{
${ }^{1}$ This methodology is also followed, for example, by Hawthorne and Srinivasan (2013), and BroncanoBerrocal and Simion (2021).

${ }^{2}$ For example, Williamson $(2000,79)$ holds that knowledge is more valuable than mere true belief because "present knowledge is less vulnerable than mere present true belief to rational undermining by future evidence".

${ }^{3}$ There are a few exceptions, such as Hawthorne and Srinivasan (2013), Miragoli and Simion (2020), and Broncano-Berrocal and Simion (2021). What are the advantages of our gnostic account compared to the previous ones? In this paper we focus more on source epistemic properties (i.e., properties of the method of belief formation) to deal with disagreement, whereas the previous gnostic accounts focus more on state epistemic properties (i.e., properties of the belief itself). But these approaches are compatible.
} 
(2019), if we employ a useful distinction in normativity theory between evaluative and prescriptive norms, we can distinguish two readings of $(\mathrm{Q}){ }^{4}$ On the one hand, evaluative norms are primarily about what is good or valuable; ${ }^{5}$ they are concerned with an ought-to-be. Thus, in this sense such norms are "evaluations of (e.g.) properties, objects, events or states of affairs" (McHugh 2012, 10). For example, we can have an evaluative norm for schools (ENS) that says "a good school is a safe school (i.e., schools ought to be safe)". Or, more simple cases, such as "a good driving is safe driving", "a good knife is sharp", and so on. Since we are just attributing value to something and not prescribing a certain course of conduct for agents, "evaluations do not presuppose accountability or blameworthiness" (McHugh 2012, 10).

On the other hand, prescriptive norms are mainly about what one ought to do. ${ }^{6}$ According to McHugh $(2012,9)$, "they require, permit or forbid certain pieces of conduct on the part of agents, and are apt to guide that conduct". For instance, we can have a prescriptive norm for schools (PNS) that says "the school board ought to hire school safety monitors". In this case, the norm PNS prescribes a certain conduct for the school board. And the school board is responsible if it fails to comply with PNS. For, we are accountable to prescriptive norms, "in the sense that violating them is liable to leave us open to blame" (McHugh 2012,9). The same is true of other prescriptive norms, such as "Drive $50 \mathrm{~km} / \mathrm{h}$ within city bounds" or "Don't steal".

Despite being distinct norms, there is a relation between evaluative norms and prescriptive norms. For, evaluative norms often have implications for prescriptive norms; namely, we can often derive a prescriptive norm from an evaluative norm. Precisely because prescriptive norms serve to make it likely that the evaluative norms will be met. For instance, a prescriptive norm, such as PNS, serves to make compliance with an evaluative norm, such as ENS, more likely. Thus, "evaluative norms often come first and prescriptive norms are in their service" (Simion, Kelp, and Ghijsen 2016, 386).

However, "these implications may not be straightforward" (McHugh 2012, 10); for, it is possible to violate an evaluative norm without violating a prescriptive norm. For instance, back to our example about school safety,

\footnotetext{
${ }^{4}$ Some people, like Wedgwood (2007), think that notions like "ought" have many different readings. Here we want to explore only the readings proposed by McHugh (2012), Simion, Kelp, and Ghijsen (2016), and Simion (2019).

${ }^{5}$ Following Geach (1956), goodness or value is used in this context in an attributive sense.

${ }^{6} \mathrm{We}$ can hold that prescriptive norms in epistemology are equivalent to "decision procedure rules" in ethics.
} 
the school board may have complied with PNS, while ENS may be violated, if the people working as school safety monitors are negligent, or incompetent, etc. And it is possible to violate a prescriptive norm without violating an evaluative norm. For example, it is possible that the school board fails with PNS because it does not hire security monitors, while ENS may be complied, if teachers and the school board decide to work overtime to monitor school safety. ${ }^{7}$

Based on this normative framework, our initial question (Q), about what are the epistemic norms for disagreements, can be understood as an evaluative question (EQ) and as a prescriptive question (PQ):

(EQ) What is the good epistemic doxastic attitude in cases of disagreement?

(PQ) What ought one to do, epistemically speaking, in cases of disagreement?

An evaluative norm for disagreement answers such questions by determining what counts as a good doxastic attitude in the face of disagreement. And a prescriptive norm for disagreement determines what one ought to do in the face of disagreement. ${ }^{8}$

\section{Arguing for Gnostic Disagreement Norms}

As emphasized in the introduction, we accept gnosticism, that is, the account that the fundamental epistemic good is knowledge. 'Gnosticism' is a term introduced by Clayton Littlejohn to refer to

\footnotetext{
${ }^{7}$ This framework, involving the distinction between evaluative norms and prescriptive norms, is not accepted by some philosophers, such as Hughes (2021b). Thanks to an anonymous referee for alerting us to these criticisms of the framework we are using. While our aim here is not to react to each of these criticisms, we can briefly summarize the objections and our responses. Hughes' first objection is that we can straightforwardly derive prescriptive norms with the same content as evaluative norms from evaluative norms. We grant that this can happen; but in the specific context of disagreement, as we develop and justify it in the next sections, it makes sense to understand the contents of the evaluative and prescriptive norms of disagreement as different. Hughes' second objection is that there are circumstances in which a prescriptive norm, such as the one we propose, does not do the job that prescriptive norms are supposed to do. But we argue in the next sections that this problem does not seem to affect our prescriptive norm of disagreement, given that such a norm is reasonably conducive to action and informative for beings like us. And Hughes' last objection is that, in cases in which being rational is hard, further norms (such as 'undergo anti-bias training') can emerge. But we can minimize this problem by developing our prescriptive norm of disagreement in terms of virtues, as we do in the next sections. A detailed analysis of all the objections presented by Hughes (2021b) will be addressed on another occasion.

${ }^{8}$ Typically, these questions are not answered in the literature on disagreement.
} 
the view that there is one and only one fundamental epistemic good and that that good is knowledge. On this view, the beliefs that realize the fundamental good are the ones that constitute knowledge. (Littlejohn 2017, 227)

It can be argued that gnosticism is the best view of epistemic value; see, for example, Williamson (2000), Hyman (2015), Littlejohn and Dutant (2021) on the value of knowledge as an argument for gnosticism. Timothy Williamson argues that knowledge is more valuable than mere true belief; for, knowledge is more stable, namely

one's belief in a proposition $p$ is more robust to evidence if one knows $p$ than if one merely believes $p$ truly; one is less likely to lose belief in $p$ in the course of interacting with the environment by discovering new evidence which lowers the probability of $p$. (Williamson 2000, 8)

Moreover, we also want to draw attention to the hitherto neglected interaction between gnosticism and disagreement, aside from Simion's recent series of publications (see, for example, Miragoli and Simion 2020; and Broncano-Berrocal and Simion 2021). It is with this gnostic assumption that we want to answer (Q). Thus, if gnosticism is true, how to answer (EQ) and (PQ)? Our proposal is as follows:

Gnostic evaluative norm of disagreement (END): In cases of disagreement about whether $p$, one holding steadfast $p$ is a good doxastic attitude if and only if one knows that $p$.

Gnostic prescriptive norm of disagreement (PND): In cases of disagreement about whether $p$, one must: hold steadfast $p$ if and only if one has good cognitive dispositions in believing that $p$ (that is, in forming or retaining the belief $p$, one exhibits dispositions that tend to manifest epistemic quality statesknowledge - in normal counterfactual cases).

In this account, the evaluative norm (END) comes first and determines what counts as a good doxastic attitude in the face of disagreement, namely it states that a good steadfast position qualifies as knowledge. From (END) we derive the prescriptive norm (PND), which determines what one ought to do in the face of disagreement, namely it prescribes that only virtuous beliefs, resulting from good cognitive dispositions (i.e. good dispositions 
about belief formation and retention), should be held steadfast. ${ }^{9}$ However, in the case of a bad cognitive disposition, such a gnostic approach prescribes changing the doxastic attitude in a way conducive to knowledge through conciliation with the interlocutor, if the latter has better cognitive dispositions with respect to the disputed belief about whether $p \cdot{ }^{10}$ If none of the subjects of the disagreement about whether $p$ has knowledge or better cognitive dispositions than their interlocutor, and such cognitive dispositions of these subjects are equally bad, then it seems that the most reasonable thing to do is to suspend judgment or belief, such as Hawthorne and Srinivasan (2013) suggests for similar norms. In the last section we will apply our gnostic norms of disagreement to practical cases to analyse when it is appropriate to follow a steadfast view or, instead, a conciliatory view.

We want to underline that the proposed norms are applied to cases of disagreement with outright belief. However, disagreements can also involve credences. For instance, I may have a .8 credence in $p$, whereas my interlocutor has a .4 credence in $p$. Can the proposed framework explain how we ought to update our credences in cases of disagreement? If so, how? First of all, our gnostic norms of disagreement were initially intended only for cases of outright belief. Second, we can somehow adapt our norms for credence cases. Following a gnostic or knowledge-first epistemology, namely the strategy proposed by Williamson (2021c), credences can be understood operationally as species of belief. Specifically, we can hold that a credence that $p$ reduces to a belief in a proposition about the probability of $p$. For instance, a credence of .9 that the ticket will lose reduces to a belief with the content that the probability the ticket will lose is .9. And such a belief can constitute knowledge. So, a person can know and believe that the probability that her ticket will lose is .9 , even though she does not know and believe that her ticket will lose. Thirdly, based on this understanding of credences, we can easily apply our gnostic evaluative norm of disagreement to credence cases in the following way: In cases of disagreement about whether $p$ (where $p$ is a belief with the content about the probability of a proposition $q$ ), one holding steadfast $p$ is a good doxastic attitude if and only if one knows that $p$. Something similar can be said in relation to the gnostic prescriptive norm (PND). ${ }^{11}$

\footnotetext{
${ }^{9}$ This is inspired by Williamson (2021a, 2021b), Lasonen-Aarnio (2021a, 2021b). We want to maintain that Williamson's strategy for the epistemic norm of belief can be replicated for the epistemology of disagreement. According to Williamson, the epistemic norm governing belief is knowledge: believe that $p$ only if you know that $p$. And from such a norm, Williamson (2021a) derives a norm for evaluating agents according to which one ought to manifest knowledge-conducive cognitive dispositions. For other accounts of gnostic disagreement norms, see Hawthorne and Srinivasan (2013) and Miragoli and Simion (2020).

${ }^{10} \mathrm{We}$ are grateful to an anonymous referee for alerting us to this point.

${ }^{11}$ Many thanks to Bruno Jacinto and an anonymous referee for pressing us on this.
} 
Such (PND) gives a general guide for action that serves to make compliance with (END) likely. That is so because, in general, good cognitive dispositions typically generate knowledge and bad cognitive disposition typically do not generate knowledge. More specifically, cognitive dispositions are classified as "good" or "bad" according to the quality of the epistemic states they tend to manifest across normal counterfactual cases (in which knowledge is the best quality status). Here we are understanding normal counterfactual cases as non-deviant cases relative to the subject of evaluation, but where the type of situation and the disposition manifested are very similar (to the actual case).

In order to further clarify the previous point, we can give some examples. For instance, dispositions to form or retain beliefs based on "wishful thinking" or whims are bad cognitive dispositions, since beliefs formed through such dispositions do not tend to lead to quality epistemic states across a relevant range of normal counterfactual cases. The same goes, in general, for dispositions to ignore testimony from reliable sources or from experts. However, a disposition to form or retain perceptual beliefs as a result of ordinary perception is a good cognitive disposition, because beliefs formed through this disposition tend to lead to quality epistemic states across a relevant range of normal counterfactual cases.

Our gnostic prescriptive norm of disagreement (PND) could be formulated in other terms. For example, in a recent paper, Littlejohn and Dutant (2021) propose that it is rational for one to believe that $p$ if and only if it is probable that one knows that $p$. This account could be adapted to serve the role of a prescriptive norm for disagreement according to which, in cases of disagreement about whether $p$, one must: hold steadfast $p$ if and only if it is probable that one knows that $p .{ }^{12}$ In normal cases (i.e., non-deviant cases, such as non-skeptical cases), there seems to be a correspondence between Littlejohn and Dutant's (2021) adapted norm and our prescriptive norm. For, if $S$ has good cognitive dispositions in believing that $p$ (namely, dispositions that tend to lead to knowledge in normal counterfactual cases), then it is probable that $S$ knows that $p$. However, we prefer our formulation of the gnostic prescriptive norm in terms of dispositions, because even in bad scenarios (such as the Evil Demon world cases or Gettier-cases), in which it is not probable that $S$ knows that $p, S$ may still have good cognitive dispositions, given that dispositions are evaluated with respect to normal counterfactual cases. For example, a person who is deceived by an evil Cartesian demon does not know propositions about her surroundings based on her perception. Even so, the dispositions manifested by such a person

\footnotetext{
${ }^{12}$ Many thanks to an anonymous referee for pressing us on this.
} 
in forming perceptual beliefs may be good, if in normal counterfactual cases such dispositions are conducive to knowledge.

But what are the arguments for our Gnostic Disagreement Norms? Starting first by presenting the main argument for (PND), we want to highlight that:

1. A good prescriptive norm satisfies the following desiderata: (i) it makes compliance with (END) probable, (ii) it is an adequate guide to action or at least is informative, and (iii) it preserves, in general, the tie between what agents ought to do and the praiseworthiness/blameworthiness of the agent's actions.

2. (PND) satisfies the proposed desiderata better than the rival accounts.

3. Therefore, (PND) is a good prescriptive norm.

We think premise 1 follows from the definition of prescriptive norms. It is worth remembering, as we presented in the initial part of this paper, that the function of the prescriptive norm is to reinforce behavior conducive to compliance with the evaluative norm (this is the first desideratum). Concomitantly, in order for us to perform such a function, the prescriptive norm needs to be informative, giving us some guide to action (this is the second desideratum). As such, we are accountable to prescriptive norms, in the sense that in typical circumstances we can be blamed of violating them or we can be praised for complying with them (this is the third desideratum). These desiderata are part of the description of the initial framework as proposed by McHugh (2012), Simion, Kelp, and Ghijsen (2016), and Simion (2019).

Concerning the second premise, the main rival account seems to be a prescriptive knowledge norm. But the prescriptive norm of disagreement cannot be understood as a knowledge norm simpliciter. For, such knowledge norm is not an operationalizable guide for action; namely, because knowledge is a non-luminous condition (see Hawthorne and Srinivasan 2013). Thus, given our limited perspective on the world, we often don't have access to facts about where the knowledge is, and so a prescriptive knowledge norm doesn't provide us with an adequate guidance about what to do, thereby violating the second desideratum. However, (PND) seems to be a more operationalizable guide for action. ${ }^{13}$ At least, even if there is no fully operational epistemology (see Williamson 2014a), generally it seems feasible for us and accessible from the subject's

\footnotetext{
${ }^{13}$ Arguments for an epistemology with guidance see, for example, Gibbons (2013) and Fassio and Gao (2021). In contrast, for an epistemology without guidance, see Hughes (2021a).
} 
standpoint to attempt to develop virtuous dispositional traits, such as "be open-minded", "be conscientious", and so on.

Even accepting the general lack of luminosity, and hence the idea that norms are not fully operational, we can take the view that norms can be more or less informative as a guide for action. ${ }^{14}$ Namely, we can argue that a dispositional norm, such as (PND), is more informative as a guide for action than a knowledge norm simpliciter. For, a norm that prescribes the development of epistemic virtues (with concrete examples of "being openminded", "following the evidence", "considering objections", etc.) seems more informative, as a guide for action towards a gnostic goal, than a norm that merely says to believe propositions we know. However, even holding that our gnostic prescriptive norm of disagreement is informative, we also concede that developing virtuous dispositions is not always accessible from the subject's standpoint. For example, consider the case of the Benighted Cognizer, adapted from Goldman by Simion, Kelp, and Ghijsen (2016, 382):

Ben is a member of an isolated and benighted community. Many of his methods of belief formation have no connection to truth whatsoever, but they are common lore in Ben's community. Let's suppose that Ben wants to know the best time to sow his crops. According to the lore of his community, in order to achieve this, he will first have to sacrifice a goat and bury it in a sacred place. Then he must sit outside his house until it starts to rain and then return to the burial place. If the sun is shining again by the time he will have arrived, it is time to sow the crops. If not, he will have to return home and continue sitting outside his house until the next rainfall. Ben has flawlessly implemented this procedure and has thereby arrived at a belief that it is time to sow the crops.

In this case, it can be argued that our gnostic prescriptive norm has no force for Ben; for, he is not in a position to develop virtuous dispositions. ${ }^{15} \mathrm{By}$ way of response we can claim that, given his circumstances, Ben is blameless for not developing better virtuous dispositions and, thus, he is blameless for violating the gnostic prescriptive norm. Thus, we can specify that the proposed disagreement norms only apply in circumstances or communities conducive to the development of virtuous dispositions.

\footnotetext{
${ }^{14}$ Broncano-Berrocal and Simion (2021) also argue that a norm can be informative even if it is not fully operational.

${ }^{15}$ Many thanks to an anonymous referee for pressing us on this.
} 
Outside of these favorable circumstances, the subject may be excused for violating the disagreement norms.

Moreover, and more importantly to support our prescriptive norm (PND), there are cases (such as the Evil Demon world cases or Gettier-cases) that do not constitute knowledge, but there is no problem in being steadfast (for example, because we are experts and our disagreeing interlocutor is a layman, or because we manifest good cognitive dispositions and our disagreeing interlocutor manifests bad cognitive dispositions) and the belief in question deserves positive evaluation and not just the attribution of "blameless", since its formation and retention manifests good cognitive dispositions.

For example, suppose we have two envatted subjects $S_{1}$ and $S_{2}$, being fed by deceptive experiences, who disagree about whether $p$. But imagine that while $S_{1}$ manifests good cognitive dispositions in forming and retaining the belief that $p, \mathrm{~S}_{2}$ manifests poor cognitive dispositions in forming and retaining the belief that $\neg p$. Given that we are faced with a sceptical scenario, neither of these subjects has knowledge; thus, if we were to follow a prescriptive knowledge norm simpliciter, we would have to conclude that both subjects should abandon their respective beliefs. However, this seems implausible, since $S_{1}$, unlike $S_{2}$, manifests good cognitive dispositions (i.e. dispositions that tend to lead to quality epistemic states in normal counterfactual cases) and therefore $S_{1}$ deserves positive evaluation. This point cannot be accommodated with a knowledge norm simpliciter, but it can be with (PND). Thus, with (PND), even victims of massive deceit deserve a kind of praise by taking a steadfast position if they have good cognitive dispositions. ${ }^{16}$

In contrast, a knowledge norm has more to do with an evaluative norm. For that reason, our main argument for (END) is as follow:

1. In cases of disagreement about whether $p$, one holding steadfast $p$ is a good doxastic attitude if and only if one's belief that $p$ is a good belief.

2. One's belief that $p$ is a good belief if and only if one knows that $p$ (see Williamson 2000).

3. Therefore, (END): In cases of disagreement about whether $p$, one holding steadfast $p$ is a good doxastic attitude if and only if one knows that $p$.

${ }^{16}$ This point is inspired by Simion, Kelp, and Ghijsen (2016), Lasonen-Aarnio (2021a, 2021b). 
As for the first premise, it is epistemically good to hold steadfast that $p$ in the face of disagreement if and only if continuing to believe $p$ is epistemically better than disbelieve or suspend judgment about whether $p$. And if so, it is because such a belief is epistemically good. Thus, at least from an objective point of view, if it is good to hold firm that $p$, then such a belief is epistemically good. And, on the second premise, we accept Williamson's argument that

\begin{abstract}
if believing $p$ is treating $p$ as if one knew $p$, then knowing is in that sense central to believing. (...) Knowing is in that sense the best kind of believing. Mere believing is a kind of botched knowing. In short, belief aims at knowledge. (Williamson 2000, 47)
\end{abstract}

Thus, we can conclude that (END). And we have (PND) in order to make compliance with (END) likely.

\title{
4. Applying the Gnostic Disagreement Norms
}

In this last section we want to apply our Gnostic Disagreement Norms to particular cases of disagreement in order to verify the behaviour of our norms. To fulfill this task, we begin with the following question: Does the higher-order evidence from disagreement give $S$ a defeater for his belief? ${ }^{17}$ In other words, does learning that a person disagrees with you about $p$ give you a defeater for $p ?^{18}$

Given the centrality of gnosticism in this paper, we follow a gnostic epistemology of defeaters according to which defeaters are evidence that the subject is not in a position to know the target proposition (see Gibbons 2013; Baker-Hytch and Benton 2015; Littlejohn and Dutant 2021). So, defeaters are indicators of ignorance; evidence that if the subject were to believe, her belief would fail to constitute knowledge. For instance, consider the following case (see Lasonen-Aarnio 2010):

At time $t 1$ Suzy sees a wall that appears red to her. On this basis, Suzy believes that the wall is red-let's call this proposition $p$. There is nothing abnormal about her perceptual abilities. At a slightly later time $t 2$ she learns a proposition $q$

\footnotetext{
${ }^{17}$ This formulation of the question is common in the disagreement literature, e.g., Frances and Matheson (2018), Matheson (2021). Higher-order evidence is evidence about our evidence. There is also good recent literature on defeaters, such as Brown and Simion (2021).

${ }^{18}$ As Matheson (2021) stresses, such questions are relevant in discussing the epistemology of disagreement.
} 
from a highly reliable and trustworthy authority, that there is a red light shining on the wall. ${ }^{19}$

In this case at $t 2$ Suzy acquires evidence and a proposition $q$ that she is not in position to know that $p$. Thus, it is not rational for Suzy to continue to believe $p$. However, is knowledge always defeated by higher-order evidence (for example, by evidence learned in face of disagreement)? We want to underline that knowledge is not always defeated. For, firstly, not all instances of higher-order evidence are indicators of ignorance (see Hawthorne and Srinivasan 2013, 13). For example, where only one of two parties in disagreement is an expert (or has more evidence than the other), it seems that one can continue to know in the face of disagreement. ${ }^{20}$

Secondly, even if higher-order evidence constitutes an indicator of ignorance, it is possible to have improbable knowing, which is an instance of KK failure ${ }^{21}$ (see Williamson 2014b). In other words, it can be likely on $S$ 's evidence that $S$ doesn't know $p$ (and, thus, $S$ has an indicator of ignorance), but $S$ knows $p$. To see this, consider a simple case (see Williamson 2014b, 972):

[T] he unconfident examinee answers questions on English history under the impression that he is merely guessing. In fact, his answers are correct, and result from lessons on it that he has completely forgotten he ever had. The example can be so filled in that it is extremely improbable on the examinee's evidence that he had any such lessons (...); nevertheless, he does know the historical facts in question. ${ }^{22}$

Williamson $(2014 b, 979)$ also present a more complex case. He argues that, given the limits of our discriminatory capacities and margin for error, a subject $S$ can know that $p<$ the pointer on the dial is within a certain range Q>, although it's improbable on $S$ 's evidence that $S$ knows that $p$.

And, lastly, a subject can acquire a defeater for $p$ and, thus, an indicator of ignorance, and such a subject may still have knowledge that $p$, or more properly, unreasonable knowledge as Maria Lasonen-Aarnio (2010) calls it. Following Lasonen-Aarnio (2010)'s reasoning, at $t 1$ a subject $S$ can have a belief $p$ that is well-based and and safely true. And, although at a later

\footnotetext{
${ }^{19}$ This case is an example of undercutting defeat.

${ }^{20}$ It is worth remembering that, as we stressed at the beginning of this paper, our methodology aims to address all cases of disagreement.

${ }^{21}$ I.e., a case of knowing something even though one does not know at the time that one knows that thing.

${ }^{22}$ Such example is not intended to show that knowledge and belief come apart.
} 
time $t 2$ such $S$ can acquire a defeater (for instance, misleading higher-order evidence against $p$ ), if $S$ simply retains her belief $p$ on the same basis as before, then it does not follow that her belief $p$ is no longer well-based and and safely true. Thus, $S$ can continue to know $p$ at $t 2$ (despite not having a reasonable belief, given that it manifests bad cognitive dispositions).

Thus, applying this reasoning to cases of disagreement, we can hold that it is possible to have knowledge in face of disagreement. For, (i) not all instance of disagreement gives us defeaters (for example, in cases where we are the only expert); and (ii) in cases in which we really acquire a defeater in a disagreement case, it is possible to have improbable knowing or unreasonable knowledge. So, it is possible to comply with (END) in the face of disagreement.

But, even if knowledge is not defeated in cases of disagreement, there are many cases in which ignoring defeaters is not a good cognitive disposition. For instance, in general, in cases of disagreement, ignoring high-order evidence from reliable sources does not manifest a good cognitive disposition, since beliefs formed through such a disposition do not tend to lead to quality epistemic states across a relevant range of normal counterfactual cases. In short, by ignoring a defeater one can continue to have knowledge, but in general, by doing so, one is not manifesting good cognitive dispositions. ${ }^{23}$ Thus, in such cases we are not complying with (PND). In order to better articulate this point, let's look at some particular cases of disagreement:

Competent Mathematician Case (adapted from Williamson 2021b): Mary is a competent mathematician and she has just proved a surprising new theorem. She shows her proof to several distinguished senior colleagues, who all tell her that it involves a subtle fallacy. She cannot quite follow their explanations of her mistake [and she ignores such objections]. In fact, the only mistake is in their objections, obscured by sophisticated bluster; her proof is perfectly valid.

In this case we can say that, even if Mary is complying with (END), she is not complying with (PND). For, the disposition to ignore the testimony of experts/seniors, in cases like theses (in which it is not feasible to discriminate between misleading counter-evidence and correct counter-

\footnotetext{
${ }^{23}$ As Lasonen-Aarnio (2021b) maintains, "even knowing is compatible with manifesting dispositions that lead one astray across a range of relevant counterfactual cases".
} 
evidence), does not tend to lead to quality epistemic states across a relevant range of normal counterfactual cases. ${ }^{24}$

Restaurant Case (adapted from Christensen 2007): We go to dinner, and we agreed to split the bill evenly, adding $20 \%$ tip. We each mentally calculate our share, and I become highly confident that our shares are $43 €$, whereas you become highly confident that we each owe $45 €$. How should I react to my colleague's belief?

According to (PND), it is not correct to follow a steadfast position in this case, since a disposition to ignore an epistemic peer in this case, in which one could easily make a mistake, does not tend to lead to quality epistemic states across a relevant range of normal counterfactual cases. Namely, if we remain inflexible and do nothing else, like a careful recalculation, there is no way available to us to choose between who is right that would track what is best across a range of counterfactual cases. ${ }^{25}$

Elementary Math Case (adapted from Lackey 2010): Harry and I are equally competent colleagues. We were drinking coffee and trying to determine how many people from our department will be attending the upcoming Workshop. I say: "Mark and Mary are going on Thursday, and Sam and Stacey are going on Friday, and since $2+2=4$, there will be four other members of our department at that Workshop". In response, Harry asserts, "But $2+2$ does not equal 4". How should I react to my colleague's belief?

According to (PND), it is appropriate to follow a steadfast position in this case, because a disposition to ignore a peer in this case, about a very elementary math equation (a proposition on which I am strongly justified and that it is rooted in the ways I reason), tend to lead to quality epistemic states in normal counterfactual cases.

In short, what does our Gnostic Prescriptive Norm prescribe? According to (PND), in Competent Mathematician Case and in Restaurant Case, it is not correct to follow a steadfast position, since agents in such cases are not

\footnotetext{
${ }^{24}$ For a similar case and diagnosis, see Lasonen-Aarnio (2010, 2021b), and Williamson (2021b). However, following Sosa's (2021) epistemology, we may have a different diagnosis; since, in order to have "first-hand knowledge", an agent may ignore criticism from well-qualified sources (see Carter 2021). But it can be argued that the Competent Mathematical Case is not an instance of first-hand knowledge, but an instance of more social or testimonial knowledge; for, the agent wants to share information with her scientific community and, in this case, the defeaters are relevant (see Greco 2020).

${ }^{25}$ For a similar case and diagnosis, see Lasonen-Aarnio $(2019,175)$.
} 
manifesting good cognitive dispositions. While in Elementary Math Case, it is appropriate to follow a steadfast position, since the agent in question is exercising a good cognitive disposition. But from an evaluative point of view, in all these cases it is possible that agents are complying with (END). However, it is worth remembering that (END) is primarily about what is good and not about what one ought to do. Ideally there would be a correspondence between (END) and (PND). ${ }^{26}$ When there is no such correspondence, we have (PND) as a guide for action in face of disagreement, since (PND) has priority when it comes to prescription and agent action. ${ }^{27}$

\section{Acknowledgments}

We are grateful to Bruno Jacinto, Ricardo Santos, Mona Simion, and Christoph Kelp for helpful comments and discussion of an earlier version of this paper. Earlier versions of this paper have been presented at the Agreement and Disagreement Conference (University of Kent), the 14th Conference of the Italian Society for Analytic Philosophy (Noto), the ArgLab Open Seminar (IFILNOVA), and the LanCog Social Epistemology Workshop (CFUL). We are grateful to the audience for helpful discussion. Special thanks to two anonymous referees for their generous comments that helped us improve this paper. Any errors or omissions are our responsibility. Work for this paper was supported by the post-doctoral project CEECIND/01066/2017 of the Portuguese Foundation for Science and Technology.

\section{REFERENCES}

Baker-Hytch, Max, and Matthew A. Benton. 2015. "Defeatism Defeated." Philosophical Perspectives 29 (1): 40-66.

\footnotetext{
${ }^{26}$ Williamson (2021a) accepts a similar point, arguing that a properly functioning system is one that meets a "local norm", such as (END), and a "global norm", such as (PND).

${ }^{27}$ We can consider that in these cases there is no normative conflict, because there is some kind of order of priority between the two norms (END) and (PND). Namely, when the point of evaluation concerns what should be done in practice and as a guide to action, (PND) has priority. For a similar point, see Simion (2021). However, as objection it can be point out that an alternative approach to the epistemology of disagreement is to have a two-pronged account similar to the one we propose, but to think of cases in which the knowledge norm and the dispositional rationality norm conflict as epistemic dilemmas (see, e.g., Hughes 2019 who advocates this approach to disagreement). By way of response, we can say that the dilemmic view isn't action-guiding and, furthermore, we can stress that our initial framework, on which we base our gnostic norms of disagreement, is not 'dilemmic' given the distinction we draw between evaluative and prescriptive norms. Hughes (2021b) himself acknowledges that if this framework is plausible, there is no 'dilemmic epistemology'. Many thanks to an anonymous referee for pressing us on this.
} 
https://doi.org/10.1111/phpe.12056.

Broncano-Berrocal, Fernando, and Mona Simion. 2021. "Disagreement and Epistemic Improvement." Synthese 199: 14641-14665.

https://doi.org/10.1007/s11229-021-03437-5.

Brown, Jessica, and Mona Simion, eds. 2021. Reasons, Justification, and Defeat. Oxford University Press.

Carter, Adam. 2021. "Collateral Conflicts and Epistemic Norms." In Epistemic Dilemmas: New Arguments, New Angles, edited by Kevin McCain, Scott Stapleford, and Matthias Steup. London and New York: Routledge.

Christensen, David. 2007. "Epistemology of Disagreement: The Good News." Philosophical Review 116 (2): 187-217.

https://doi.org/10.1215/00318108-2006-035.

Fassio, Davide, and Jie Gao. 2021. "Do We Really Need a Knowledge-

Based Decision Theory?" Synthese 199: 7031-7059.

https://doi.org/10.1007/s11229-021-03104-9.

Frances, Bryan, and Jonathan Matheson. 2018. "Disagreement". The Stanford Encyclopedia of Philosophy, edited by Edward N.

Zalta. https://plato.stanford.edu/entries/disagreement/

Geach, Peter. 1956. "Good and Evil." Analysis 17 (2): 33-42.

https://doi.org/10.1093/analys/17.2.33.

Gibbons, John. 2013. The Norm of Belief. Oxford: Oxford University Press.

Greco, John. 2020. The Transmission of Knowledge. Cambridge:

Cambridge University Press.

https://doi.org/10.1017/9781108560818.

Hawthorne, John, and Amia Srinivasan. 2013. "Disagreement Without

Transparency." In The Epistemology of Disagreement, 9-30.

Oxford: Oxford University Press.

https://doi.org/10.1093/acprof:oso/9780199698370.003.0002.

Hughes, Nick. 2019. "Dilemmic Epistemology." Synthese 196 (10): 4059-

90. https://doi.org/10.1007/s11229-017-1639-x.

. 2021a. "Epistemology Without Guidance." Philosophical Studies,

179: 163-196. https://doi.org/10.1007/s11098-021-01655-8.

.2021b. "Epistemic Dilemmas Defended." In Epistemic Dilemmas, edited by Nick Hughes. Oxford: Oxford University Press.

Hyman, John. 2015. Action, Knowledge, and Will. Oxford: Oxford University Press.

Lackey, Jennifer. 2010. "What Should We Do When We Disagree?" In Oxford Studies in Epistemology, edited by John Hawthorne and Tamar Szabó Gendler, 274-93. Oxford: Oxford University Press. Lasonen-Aarnio, Maria. 2010. “Unreasonable Knowledge.” Philosophical Perspectives 24 (1): 1-21.

https://doi.org/10.1111/j.1520-8583.2010.00183.x. 
2019. "Guidance, Epistemic Filters, and Non-Accidental OughtDoing." Philosophical Issues 29 (1): 172-83.

https://doi.org/10.1111/phis.12166.

2021a. "Perspectives and Good Dispositions." Philosophy and Phenomenological Research.

2021b. "Dispositional Evaluations and Defeat." In Reasons, Justification, and Defeat, edited by Jessica Brown and Mona Simion, 93-115. Oxford: Oxford University Press. https://doi.org/10.1093/oso/9780198847205.003.0005.

Littlejohn, Clayton, and Julien Dutant. 2021. "Defeaters as Indicators of Ignorance." In Reasons, Justification, and Defeat, edited by Mona Simion and Jessica Brown, 223-246. Oxford: Oxford University Press.

https://doi.org/10.1093/oso/9780198847205.003.0010.

Littlejohn, Clayton. 2017. "La Verdad En El Gnosticismo." Análisis Revista de Investigación Filosófica 3 (2): 217.

https://doi.org/10.26754/ojs_arif/a.rif.201621568.

Matheson, Jonathan. 2021. "Disagreement and Higher-Order Evidence." In The Routledge Handbook of the Philosophy of Evidence, edited by Maria Lasonen-Aarnio and Clayton Littlejohn. London and New York: Routledge.

McHugh, Conor. 2012. “The Truth Norm of Belief." Pacific Philosophical Quarterly 93 (1): 8-30.

https://doi.org/10.1111/j.1468-0114.2011.01413.x.

Miragoli, Martin, and Mona Simion. 2020. "Gender, Race, and Group Disagreement." In The Epistemology of Group Disagreement, edited by Fernando Broncano-Berrocal and J. Adam Carter, 12538. London and New York: Routledge. https://doi.org/10.4324/9780429022500-7.

Simion, Mona, Christoph Kelp, and Harmen Ghijsen. 2016. "Norms of Belief." Philosophical Issues 26 (1): 374-92.

https://doi.org/10.1111/phis.12077.

Simion, Mona. 2019. "Knowledge-First Functionalism." Philosophical Issues 29 (1): 254-67. https://doi.org/10.1111/phis.12152.

2021. "Scepticism about Epistemic Dilemmas." In Epistemic Dilemmas: New Arguments, New Angles, edited by Kevin McCain, Scott Stapleford, and Matthias Steup. London and New York: Routledge.

Sosa, Ernest. 2021. Epistemic Explanations: A Theory of Telic Normativity, and What It Explains. Oxford: Oxford University Press.

Wedgwood, Ralph. 2007. The Nature of Normativity. Oxford and New York: Oxford University Press. 
Williamson, Timothy. 2000. Knowledge and Its Limits. Oxford: Oxford University Press. https://doi.org/10.1093/019925656x.001.0001. - 2014a. "Knowledge First." In Contemporary Debates in Epistemology, edited by Matthias Steup, John Turri, and Ernest Sosa, 1-9. Second Edition. Wiley-Blackwell.

—. 2014b. "Very Improbable Knowing." Erkenntnis 79 (5): 971-99. https://doi.org/10.1007/s10670-013-9590-9.

- 2021a. " $E=K$, but What about $R$ ?" In The Routledge Handbook of Evidence, edited by Maria Lasonen-Aarnio and Clayton Littlejohn. London and New York: Routledge. . 2021b. "Epistemological Ambivalence." In Epistemic Dilemmas, edited by Nick Hughes. Oxford: Oxford University Press.

2021c. "Knowledge, Credence, and Strength of Belief". In Expansive Epistemology: Norms, Action, and the Social World, edited by A. K. Flowerree and Baron Reed. London and New York: Routledge. 